most cases, there are multiple reasons for burning. Survey results show the burning of wheat straw appears to be primarily a matter of convenience, to rapidly remove straw before soil preparation. The high $\mathrm{HBF}$ values for almond and walnut residues are due largely to the type of harvesting technology employed for the nuts from these crops. Tree prunings in the rows, whether shredded or not, interfere with the sweeping operation. Alternate harvesting methods or greater utilization of the prunings (such as by power plants) would reduce the need to burn.

Rice straw disposal is the key issue, and one not readily solved. While alternatives to rice straw burning do exist, none are as inexpensive as burning, and some may entail significant economic impact. If managed properly they appear to provide adequate disease control. The development of suitable alternatives, including power generation and soil incorporation, has been the subject of much research, most of which continues today. The advantages and disadvantages of harvesting and utilizing straw, or adapting agronomic practice to accommodate the straw, are many.

In reality, the debate over agricultural burning in California appears to be one of whether state policy should or should not protect burning privileges for the four crops that account for nearly all atmospheric emissions from this source. Currently, Article 3 of the Health and Safety Code expresses the legislative intent that agricultural burning should not be prohibited because of the importance to the state of a viable agricultural economy. From the public perspective, the debate over burning is not principally an economic one, because the external costs of health impacts cannot be measured, and food costs are relatively low for the majority of the population. From an agronomic standpoint, burning remains both an economic and environmental question, particularly if chemical or other means must be found to control pests and diseases that are legitimately controlled by burning.

Decisions on agricultural burning should rightly include the equitable application of regulations to forestry, which, from controlled fires, emits roughly the same amount of pollutants as agriculture. Alternatives to open burning exist, but a concerted effort by the state is needed to develop incentives for their implementation. The same can be said for the entire issue of environmental quality in California, in which agricultural burning plays a locally important, but overall minor, role.

B.M. Jenkins is Associate Professor, and S.Q. Turn and R. B. Williams are Graduate Research Assistants, Agricultural Engineering Department, UC Davis.

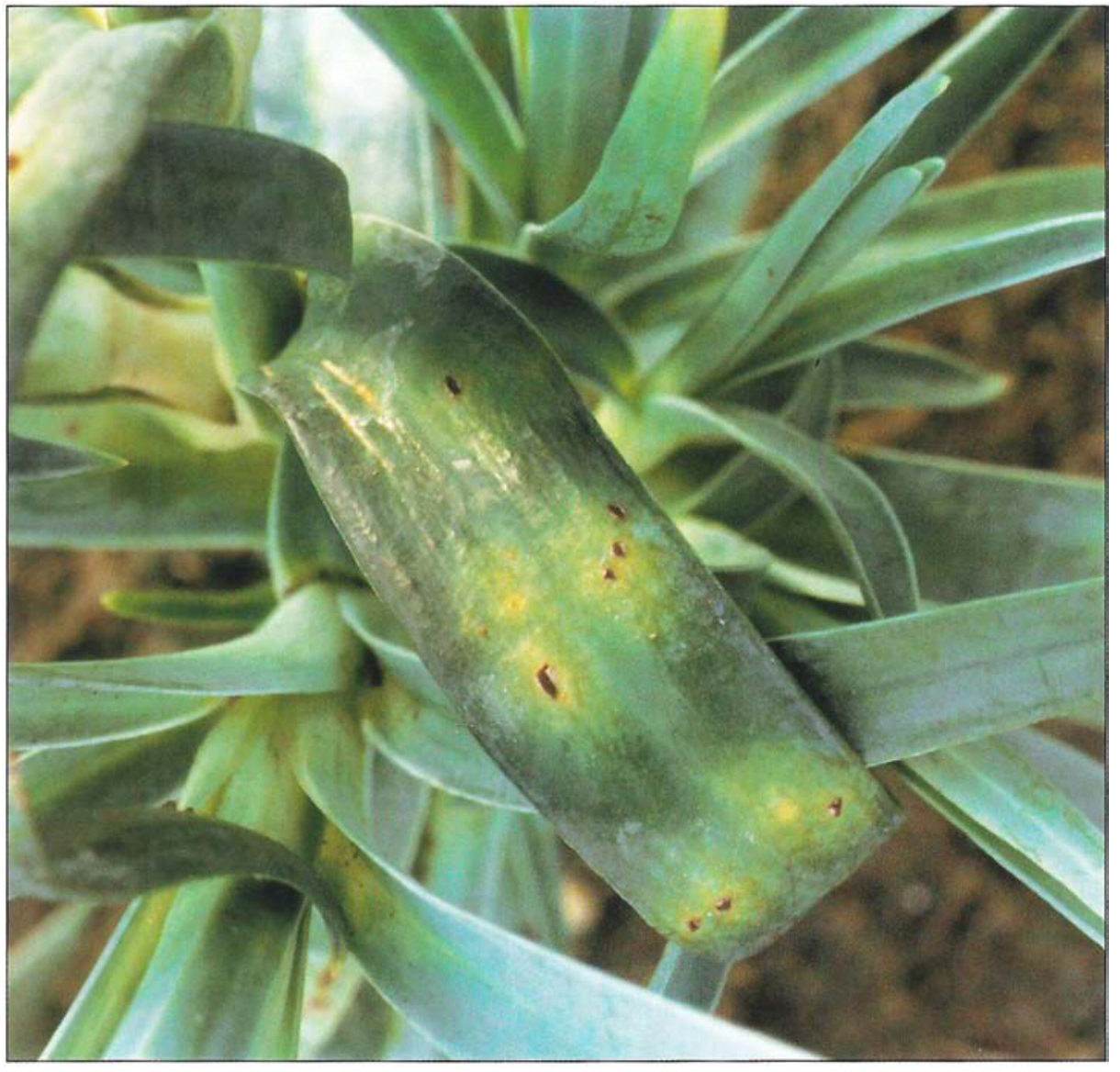

Rust on greenhouse carnations.

\title{
Tests compare fungicides for control of rust on green- house carnations
}

Donald M. Ferrin $\square$ Roberta G. Rohde

Four fungicides were tested for control of rust on greenhouse carnations. The most effective fungicides were Plantvax and Systhane; the latter is not currently registered for control of this disease in California.
Rust of carnations, caused by the fungus Uromyces dianthi, occurs commonly on greenhouse-grown carnations in coastal areas of Southern California. The disease occurs throughout the year but is most severe during the cooler, more humid periods of fall through spring when coastal fog is prevalent. The pathogen enters the plant through the stomates and grows between the host cells upon which it feeds.

Masses of the characteristic reddishbrown urediospores are produced within pustules that eventually break through the plant cuticle. These pustules can be found 


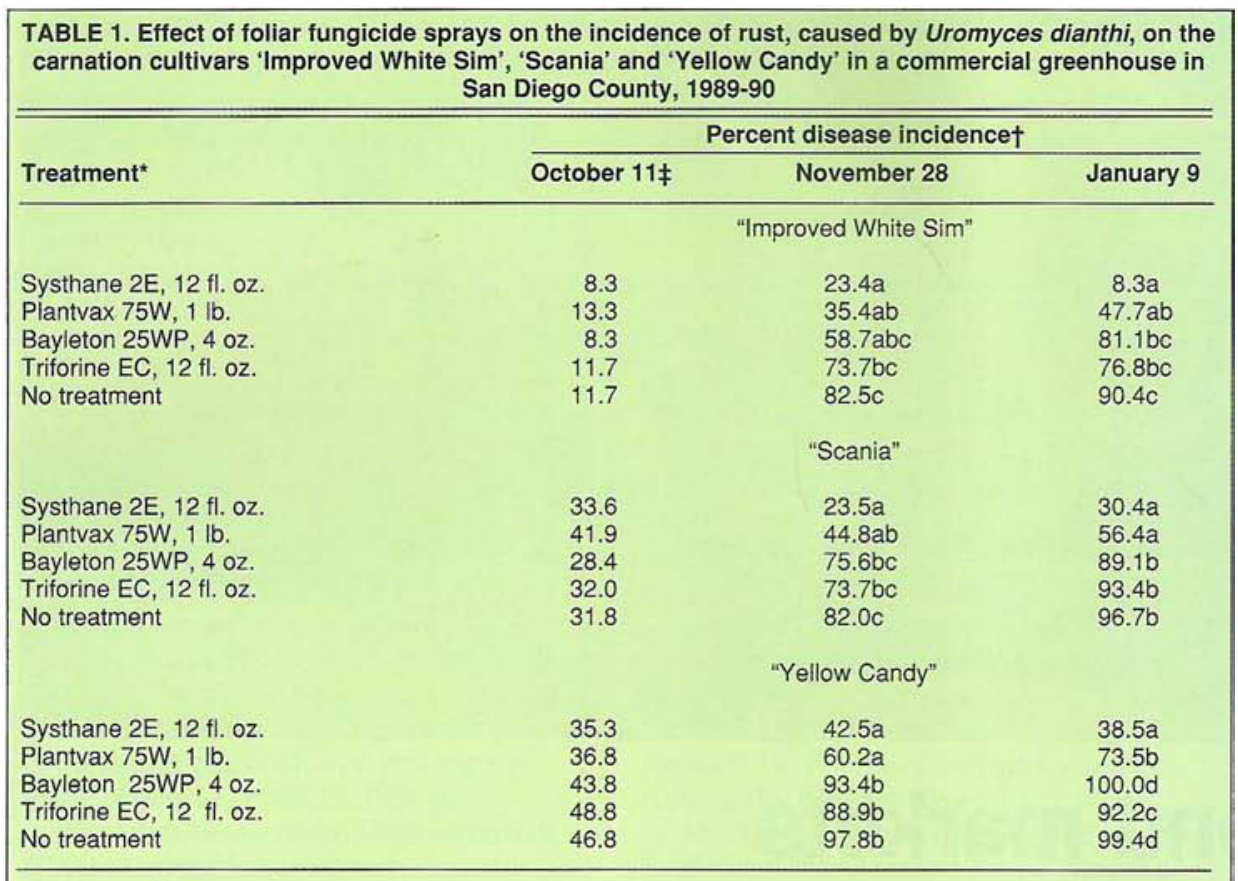

* Rate per 100 gallons of water.

†Disease incidence was calculated as the percentage of stems with rust pustules determined for 20 stems per plot. Treatment means for each cultivar and each assessment date followed by the same letter are not significantly different at the $5 \%$ level based on Duncan's multiple range test.

$\ddagger$ The assessment on October 11 was one week prior to the initiation of treatments; there were no significant differences in disease incidence among plots for any of the cultivars at this time.

TABLE 2. Effect of foliar fungicide sprays on the severity of rust, caused by Uromyces dianthi, on the carnation cultivars 'Improved White Sim', 'Scania' and 'Yellow Candy' in a commercial greenhouse in San Diego County, 1989-90

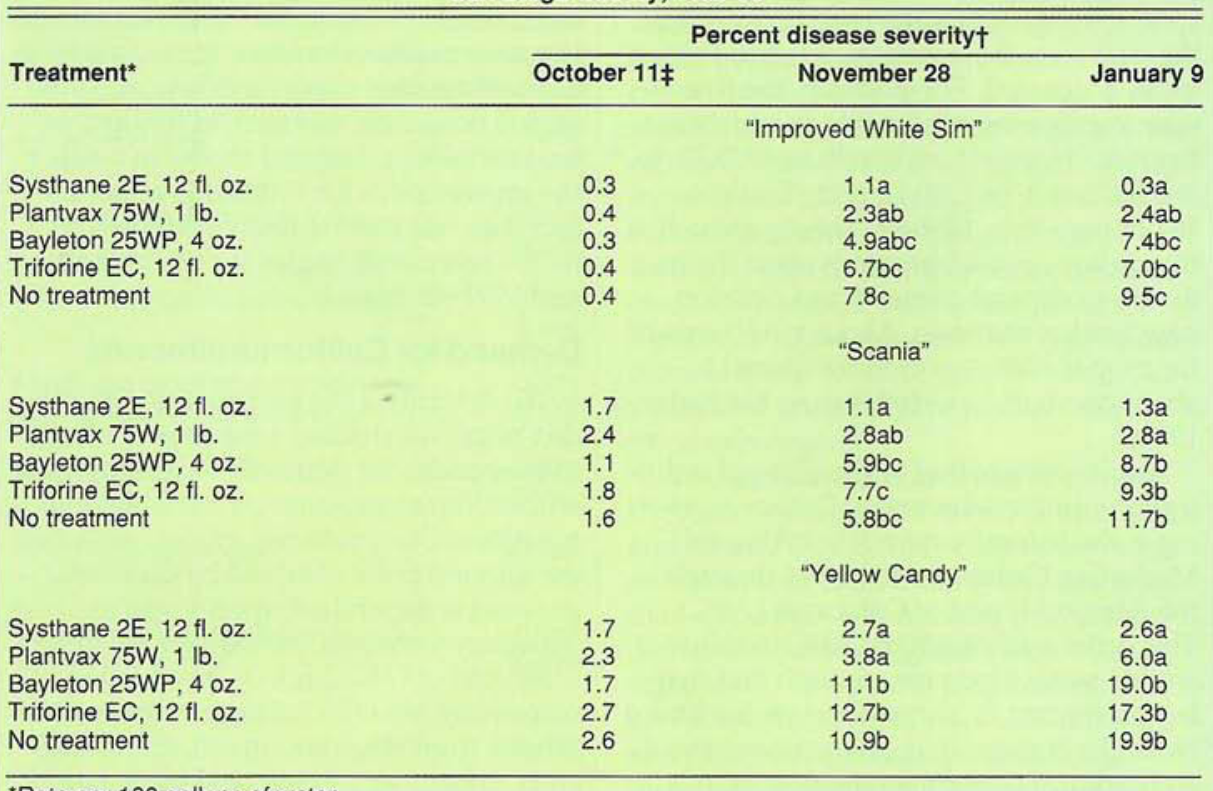

*Rate per 100 gallons of water.

tDisease severity was calculated as the percentage of the leaves and internodes with pustules determined for the upper ten nodes of twenty stems per plot. Treatment means for each cultivar and each assessment date followed by the same letter are not significantly different at the $5 \%$ level based on Duncan's multiple range test.

$¥$ The assessment on October 11 was one week prior to the initiation of treatments; there were no significant differences in disease severity among plots for any of the cultivars at this time. on both the upper and lower leaf surfaces as well as on the stems. The disease causes a loss of aesthetic quality as well as a reduction in plant vigor.

Fungicide trials were conducted on three carnation cultivars in a commercial greenhouse in Encinitas from October 18, 1989 to January 9, 1990. Fifteen plots were established within individual rows of each of the cultivars Improved White Sim, Scania and Yellow Candy. Each plot was 3.25 by 10 feet and contained 112 plants.

Five treatments were arranged in a randomized complete block design with three blocks for each cultivar. Treatments were foliar sprays of Plantvax $75 \mathrm{~W}$ (oxycarboxin), Bayleton 25WP (triadimefon), Triforine EC $18.2 \%$ (triforine), Systhane $2 \mathrm{E}$ (myclobutanil), and the nontreated control (see table 1 for the rates used). Ortho X-77 Spreader at 4 ounces per 100 gallons of water was used with all fungicides. Sprays were applied to full coverage with a 3-gallon backpack sprayer at a pressure of 44 pounds per square inch. Fungicides were applied six times at 14-day intervals beginning October $18,1989$.

Disease was evaluated 1 week prior to and 6 and 12 weeks after the initiation of fungicide spraying. Disease was assessed on the upper 10 nodes of each of 20 stems per plot and was recorded as the number of leaves and internodes with pustules. Disease incidence was calculated for each plot as the percentage of stems with at least one pustule. Disease severity was calculated for each plot as the percentage of leaves and internodes with at least one pustule.

Systhane and Plantvax were the most effective fungicides for control of carnation rust (tables 1 and 2). Systhane, which is not currently registered for use on greenhouse carnations in California, consistently out-performed Plantvax although differences generally were not significant. In the plots treated with Systhane, disease remained relatively constant over the 12week period, whereas it generally increased in the plots treated with Plantvax.

By the end of 12 weeks, plots treated with Systhane averaged $33.5 \%$ less incidence of disease than plots treated with Plantvax, but the severity of disease averaged only $2.3 \%$ less. Bayleton and Triforine were not effective for control of rust under the conditions of these tests.

D. M. Ferrin is Assistant Professor and R. G. Rohde is former Staff Research Associate, Department of Plant Pathology, UC Riverside. 